\title{
A DINÂMICA CONSCIENTE/INCONSCIENTE À LUZ DA PSICOLOGIA HISTÓRICO-CULTURAL ${ }^{1}$
}

\author{
Lígia Márcia MARTINS ${ }^{2}$
}

Resumo: $\mathrm{O}$ estudo das dimensões consciente e inconsciente do psiquismo humano marca as próprias origens da psicologia. Enfoques prevalentes ora sobre uma dimensão ora sobre outra conduziram a interpretações distintas e antagônicas que foram firmandose nas diversas matrizes do pensamento psicológico. Segundo Vygotski e seguidores, os rumos dicotômicos trilhados pela psicologia determinaram mudanças lógicometodológicas tendo em vista a ampliação dos princípios de estruturação da própria ciência psicológica. Com este empenho, se conduziram na direção da sistematização da teoria histórico-cultural, fundamentando-a nos princípios metodológicos materialistas dialéticos. Por essa via, conferiram ao psiquismo humano um enfoque unitário, pelo qual as dimensões consciente e inconsciente resultam apreendidas como polos opostos, todavia, interiores um ao outro. À luz deste referencial esse estudo tem como objetivo apresentar a concepção histórico-dialética acerca da dinâmica consciente/inconsciente, tendo em vista contribuir com a análise sistêmica dos fenômenos psíquicos. Conclui-se que o conteúdo da consciência é dado pelo significado da palavra - o não verbal resulta oculto e foge ao controle consciente; o significado da palavra se forma e se transforma na relação ativa sujeito-objeto; o psiquismo humano não se limita à sua vertente consciente, por isso é licito considerar que o inconsciente é potencialmente consciente e vice versa.

Palavras-chave: Psicologia histórico-cultural. Psiquismo. Consciência. Inconsciente.

\section{Introdução}

O estudo das dimensões consciente e inconsciente do psiquismo humano marca as próprias origens da psicologia como ciência e profissão. Enfoques prevalentes ora sobre uma dimensão ora sobre outra conduziram a interpretações distintas e muitas vezes antagônicas que foram, ao longo do tempo, firmando-se nas diversas matrizes, ou abordagens, do pensamento psicológico. Segundo Vygotski (1997) os rumos dicotômicos trilhados pela psicologia conduziram-na a problemas praticamente insolúveis, a determinarem mudanças lógico-metodológicas tendo em vista a ampliação dos princípios de estruturação da ciência psicológica. Aclarar a natureza do

${ }^{1}$ Este estudo foi elaborado tendo em vista apresentação no Simpósio Fundamentos da Psicologia Histórico-Cultural para a Atuação em Saúde Mental, integrante do VIII Congresso Internacional y XIII Nacional de Psicologia Clínica, realizado em Granada, Espanha, de 19 a 22 de novembro de 2015.

2 UNESP - Universidade Estadual Paulista "Júlio de Mesquita Filho". Faculdade de Ciências Departamento de Psicologia. Bauru - SP - Brasil. 17033-360 - ligiamar@fc.unesp.br 
comportamento especificamente humano, isto é, de um ser histórico-socialmente formado balizou os estudos deste autor ao longo de toda sua trajetória como pesquisador e foi nesse diapasão que ele destacou o problema da consciência como um dos pontos nevrálgicos para a consolidação da psicologia como uma ciência autônoma.

A nosso juízo, não obstante passado aproximadamente um século em relação às análises empreendidas por Vygotski em relação aos rumos da psicologia, as tensões entre abordagens psicológicas sobrevivem à medida que elas continuam advogando ora a centralidade na consciência, ora no inconsciente, ou, ainda, ao secundarizarem ambos os fenômenos para a explicação do comportamento humano.

Visando a superação de tais impasses consideramos premente afirmar que a vida psíquica, em todas as suas dimensões, se vai constituindo como resultado das transformações das atividades que engendram as relações vitais do indivíduo com o meio. Tal fato exige a superação de concepções centradas em fatores psíquicos prevalentes - conforme a lógica do ou isto ou aquilo, assim como exige o entendimento da subjetividade humana como conjunto de propriedades psíquicas relacionadas entre si e que, consequentemente, influenciam-se mutuamente.

Conforme Martins (2015), haja vista que uma das características nucleares da atividade humana é sua sustentação por motivos, por finalidades, há que se considerar que a existência de motivos e a consciência sobre eles são dois fenômenos distintos, do que se deduz que podem ocorrer atividades cujos motivos se encontram ocultos para o sujeito. Os motivos não conscientes, porém, possuem a mesma determinação que qualquer outro, só podendo ser reconhecido pela pessoa com o auxílio de sua relação com o mundo circundante.

Assim, na base da inconsciência de uma vivência reside a inexistência da conexão consciente atividade/motivos e, por consequência, a inexistência de uma relação adequada para com a realidade. Isso é o que gera com frequência atos e sentimentos fora do controle da consciência, isto é, inconscientes, o que significa que a inconsciência da vivência consiste precisamente no fato de não penetrar no campo da consciência, entendida, então, como percepção do fenômeno dentro do sistema de relações objetivas que o sustenta.

Todavia, como o número dessas relações é, em princípio, infinito, impossível se torna que tenhamos total consciência de todas elas, ou seja, nenhuma vivência se torna absolutamente consciente em todas as suas relações objetivas. Em contrapartida, não 
existe nenhuma vivência desligada de toda e qualquer relação objetiva, de sorte que nenhuma vivência pode ser absolutamente inconsciente.

Tendo-se que a consciência não é um lócus do psiquismo, mas uma qualidade dos processos psicológicos, o fundamento do tratamento dispensado pela psicologia histórico-cultural à questão consciência/inconsciência das vivências é sua consideração como continuum de consciência, estruturado na base das relações concretas da pessoa com a realidade vivida. Disto resulta que a consciência real sobre qualquer fenômeno é representada pela unidade correlacional entre o que se tem consciência e aquilo que permanece inconsciente.

Com base nessas considerações gerais investigamos, em produções de Vygotski, outros contributos para a compreensão da dinâmica sistêmica consciente/inconsciente, haja vista que nas referidas produções residem a gênese e os fundamentos da própria psicologia histórico-cultural.

\section{Método}

À luz da psicologia histórico-cultural este estudo tem como objetivo apresentar a concepção histórico-dialética acerca da dinâmica consciente/inconsciente, tendo em vista contribuir com a análise sistêmica dos fenômenos psíquicos. Trata-se de uma investigação de natureza metodológica bibliográfica que tem como preceito de base, para a análise da dinâmica consciente/inconsciente, a definição histórico-cultural de psiquismo como unidade material/ideal responsável pela formação da imagem subjetiva da realidade objetiva por meio das funções psíquicas em suas intervinculações e interdependências (MARTINS, 2013). Os dados em análise resultam de produções de Vygotski no período de 1925 a 1933, nos quais o autor conferiu destaque ao fenômeno da consciência.

\section{Resultados}

Para introduzir o tratamento dispensado à temática consciente/inconsciente optamos por fazê-lo localizando-a nas origens da psicologia histórico-cultural, em tempos nos quais, sobretudo Vygotski, colocava em foco a análise do objeto da psicologia como ciência. Já em 1925, em artigo denominado "A consciência como problema da psicologia do comportamento", Vygotski se posicionou radicalmente crítico em relação ao enfoque adotado pela reflexologia, apontando como um de seus 
limites à construção de um sistema psicológico que pretere o conceito de consciência. Para ele, no referido sistema:

\begin{abstract}
Apaga-se radicalmente toda diferença entre o comportamento do animal e do homem. A biologia engole a sociologia e a fisiologia à psicologia. O estudo do comportamento do homem resulta abordado do mesmo modo que o estudo do comportamento de qualquer mamífero. E, ao fazê-lo, ignora-se o que acrescentam de novo a consciência e a psique ao comportamento humano. (VYGOTSKI, 1997, p. 41).
\end{abstract}

Evidenciando sua discordância em relação à premissa da reflexologia ao pressupor a possibilidade de explicar o comportamento do indivíduo sem recorrer a fenômenos subjetivos, ou, ao inferir possível uma "psicologia sem psique" (idem, p. 42), o psicólogo bielorrusso identifica esta posição epistêmica como a outra face do dualismo próprio à psicologia subjetivista, em suas pretensões de estudar uma psique pura e abstrata. Coloca o problema da natureza da consciência no centro da psicologia científica em construção e, por coerência metodológica ao materialismo dialético, anuncia a premência por investigações que a abordem sem fissuras, sobretudo no que tange às relações entre os fenômenos conscientes e inconscientes.

No bojo da análise realizada por Vygotski aos sistemas teóricos desenvolvidos até então no campo da psicologia e sistematizada no célebre ensaio "O significado histórico da crise da psicologia". "Uma investigação metodológica”, datado de 1927, o autor retoma o problema da natureza do comportamento humano, evidenciando agora os limites da psicologia tradicional, passível de ser caracterizada como uma grande árvore, repleta de ramos, mas carente de caule! Ou seja, uma ciência multifacetada como resultado da ausência de uma base comum, a fornecer uma unidade de análise entre suas diversas correntes ou especificidades teóricas.

A carência de uma psicologia geral e, por conseguinte, de um princípio ou 'lei' geral a orientar as investigações psicológicas conduziram a inúmeros caminhos, marcados por divergências radicais em relação aos parâmetros de análise psicológica e formulações teórico-metodológicas dela decorrentes. Nessa direção, Vygotski (1997) analisa os sistemas psicológicos que cultivam dicotomias, a exemplo de individual/social, normal/patológico, consciente/inconsciente etc. Foi nessa esteira que também anunciou sua discordância em relação aos enfoques que conferem centralidade ao conceito de inconsciente tomando o comportamento patológico como critério de 
referência. Segundo o referido autor, para a psicologia tradicional dualista qualquer pessoa com uma patologia, tomada como objeto de estudo, seria alguém em maior ou menor grau normal e deveria ser definida com respeito à normalidade. Já para outros sistemas qualquer pessoa normal seria mais ou menos patológica e deveria ser interpretada como uma variação de algum tipo patológico. Nas palavras do autor:

Por conseguinte, há que se ir da patologia para a normalidade, explicar e compreender o homem normal a partir da patologia e não o contrário, como se havia feito até agora. A chave da psicologia está na patologia, e não porque esta última tenha desvelado e estudado as raízes da psique, mas sim porque esta é a natureza interna dos fatos e condiciona a natureza do conhecimento científico sobre os fatos. Se para a psicologia tradicional qualquer pessoa com uma psicopatologia é, como objeto de estudo, uma pessoa em maior ou menor grau normal e deve ser definida com respeito à normalidade, para os novos sistemas qualquer pessoa normal é mais ou menos patológica e deve, portanto, ser interpretada como uma variante de tal ou qual tipo patológico. (VYGOTSKI, 1997, p. 260).

Ao longo da exegese que faz acerca das várias correntes psicológicas em relevo nas décadas iniciais do século XX, Vygotski mapeia três posições analíticas à raiz das quais o comportamento humano vinha sendo explicado. Uma posição compreenderia os sistemas teóricos que consideram a pessoa normal como protótipo e o indivíduo patológico como uma variante do mesmo, mas que, com isso, dicotomizam o tratamento dispensado ao psiquismo entre normal e/ou patológico. Diferentemente, outros sistemas conferem centralidade ao fenômeno patológico, considerando a normalidade uma variante sua, assumindo um critério metodológico segundo o qual a natureza e a essência do fenômeno ou objeto psíquico - o inconsciente revela-se de forma mais evidente em sua manifestação extrema, patológica.

$\mathrm{Na}$ terceira posição, os embates entre normal e patológico, consciente e inconsciente desaparecem, à medida que conferem protagonismo à psicologia animal empírica. A psicologia animal impõe-se, assim como lastro para uma psicologia supostamente científica e ponto de partida para a análise objetiva do funcionamento psíquico. Todavia, alerta Vygotski (1997), a psicologia animal deriva da biologia, que formula seus construtos no âmbito das ciências da natureza, que se firmam como fontes de onde derivam os métodos investigativos e os princípios que resultam deles tendo em vista explicar o comportamento. 
Ao analisar estas três posições teóricas, Vygotski evidencia quão controversa a psicologia se revela e, mais uma vez, destaca as consequências nefastas advindas da ausência de uma base científica comum para a psicologia, isto é, de uma concepção geral e articulada que delimite o objeto da psicologia. Com esse intuito, conclama a formulação da psicologia histórico-cultural como intento de superação de tais controvérsias, haja vista que, para o autor, uma ciência geral surge da necessidade de se unir os diferentes ramos do conhecimento que, não obstante a heterogeneidade que os marca se tocam e se entrelaçam, ainda que de modo aleatório. Trata-se, pois, de buscar a construção do conhecimento na perspectiva da totalidade.

Conforme postula no artigo intitulado "A psique, a consciência e o inconsciente", datado de 1930, Vygotski chama-nos a atenção para a importância psicológica destes três termos, todavia, apela sobre eles um enfoque que supere tanto os vieses idealistas quanto materialistas mecanicistas. Para essa tarefa anuncia a necessária mudança metodológica acerca dos fenômenos psíquicos, a conduzir na direção de uma psicologia dialética. Ao propô-la, enfatiza a unidade dos processos psíquicos - no que se inclui sua base material, fisiológica, uma vez que desgarrados do conjunto todos os processos resultam incompreensíveis. Do atendimento a esta perspectiva decorrem duas afirmações basilares da psicologia histórico-cultural, quais sejam: a afirmação da natureza social do desenvolvimento humano e a definição de psiquismo como unidade material/ideal - representada pelo seu lastro orgânico/concreto e ideativo/abstrato, graças a qual se edifica a imagem subjetiva da realidade objetiva - 'mundo interior', por meio de um sistema interfuncional.

Assim concebendo o psiquismo humano, em trabalho intitulado "Sobre os sistemas psicológicos”, em 1930 Vygotski caracteriza o referido psiquismo como unidade de funções psíquicas - sensação, percepção, atenção, memória, linguagem, pensamento, imaginação, emoção e sentimento, que ao longo do desenvolvimento do indivíduo, se especializam e se complexificam graças aos nexos e conexões que entre si estabelecem. Afirma, ainda, que nos estágios iniciais do desenvolvimento tais conexões se caracterizam tanto pelo primitivismo e indiferenciação das funções quanto pelo imediatismo e espontaneidade com a qual operam.

Destarte, o autor destaca que nos anos iniciais de vida, antecedentes ao desenvolvimento da fala, o modo pelo qual o psiquismo funciona, na qualidade de amálgama indiferenciado de funções psíquicas, é completamente distinto das maneiras 
que assumirá a medida e ao longo da apropriação dos signos da cultura e especialização das funções psíquicas, sobretudo pelo domínio da palavra.

Nesta etapa primeva, a percepção subjuga-se às propriedades sensíveis do campo perceptual e a atenção, ainda fluida e espontânea, se distribui neste campo numa relação de prevalência dos estímulos distrativos sobre a atenção focal. Haja vista a incipiência da linguagem - na qualidade de sistema de signos, o campo perceptual resulta preponderante sensorial, de sorte que apenas o desenvolvimento da fala poderá convertê-lo em campo semântico, a orientar a atenção não mais pelas propriedades externas dos objetos e fenômenos, mas em razão dos significados que possuem.

Sendo a atenção uma das formas pelas quais a percepção se torna consciente, os limites da primeira repercutem diretamente sobre a segunda. Esta forma de articulação entre percepção e atenção sustenta a pouca correspondência entre a representação e aquilo que é representado da realidade vivida e, consequentemente, coloca sob suspeita a fidedignidade entre a imagem e aquilo que, de fato, ela reflete. Corrobora essa afirmação o fato de que os seres humanos são, dentre todos os animais, os que nascem com maior grau de incompletude psíquica, demandando longos anos de cuidado e educação por parte de outros seres humanos.

Ademais, as estreitas alianças entre percepção e atenção representam o substrato da memorização que, em suas etapas iniciais, resulta mecânica e imediata. Conforme Vygotski (1996), nos primeiros anos de vida já se verifica uma grande capacidade de registo e fixação de vestígios da experiência e a memória direta ou por imagens predomina ao longo desses anos. Esse tipo de registro mnêmico possibilita à criança, ainda em seus primeiros meses, o reconhecimento de pessoas e objetos que a cercam, todavia, a memorização ainda carece de organização, seletividade e, sobretudo, registro de representações abstratas, a exemplo de palavras e significados.

$\mathrm{Na}$ ausência de conceitos plenamente desenvolvidos a memorização infantil se apoia nas alianças entre percepção e atenção, culminando num tipo de registro que reproduz os limites perceptuais e atencionais. Por isso, na formação primária dos conceitos o objeto do pensamento não é a estrutura lógica do próprio conceito, mas a recordação dos traços do objeto que se fazem presentes na memória. Vygotski reitera, assim, que a memória em imagens e involuntária é o ponto de apoio inicial do pensamento, de forma que nos primeiros anos pensar não é outra coisa, senão, recordar, não obstante todos os seus vieses e limites. 
Graças ao desenvolvimento da fala e à medida das transformações qualitativas da percepção - tornada categorial e da atenção espontânea contraposta à atenção voluntária e focal, as relações entre memória e pensamento se reconfiguram, descortinando uma nova ordem de fatos: a memorização do percebido subjugada ao que é compreendido. É pois, na esteira do desenvolvimento cultural do psiquismo que a memorização, outrora sob a égide de registros assistemáticos, conquista expressões essencialmente simbólicas, nas quais o pensamento passa a ocupar o primeiro plano.

Portanto, as conexões interfuncionais sofrem profundas transformações pela mediação e internalização dos signos culturais. É, pois, a apropriação do universo simbólico representado pelo entrelaçamento entre linguagem e pensamento que descortina as mais significativas transformações do sistema psíquico, possibilitando que, continuamente, novas e mais complexas conexões interfuncionais ocorram.

Destaque-se que a imagem subjetiva resultante do sistema psíquico nas etapas iniciais da vida se revela sincrética, um emaranhado de representações que carrega consigo a elementaridade da captação sensório-perceptual, da atenção espontânea, da memória involuntária e, sobretudo, a ausência do significado simbólico do mundo e das experiências da pessoa nele, haja vista a incipiência do processo de formação de conceitos. O desenvolvimento da linguagem, mais precisamente, o desenvolvimento da fala, alçará a imagem subjetiva da realidade objetiva a novos patamares, corroborando a superação do sincretismo inicial.

Segundo Vygotski (1995, 2001), a linguagem não é apenas um meio para se compreender e influenciar os demais, mas uma forma de se compreender a si mesmo. Suas conexões com o pensamento, a quem compete captar o objeto no conjunto de relações objetivas que o sustentam e edificar conceitos aptos a representa-los por meio da palavra, operam como fator propulsor das mais decisivas transformações do sistema interfuncional que caracteriza o psiquismo humano.

Para o autor é este sistema dinâmico que baliza a consciência e a autoconsciência, numa correlação permanente entre a vida intelectual e a vida afetiva sintetizada na personalidade das pessoas. Destaca que a consciência possui estrutura semântica, instituída por significados e sentidos que orientam a relação do indivíduo com o mundo externo e interno. Nessa direção, o autor afirma o papel da palavra na constituição da referida estrutura, colocando em foco a inexistência de palavra sem significado, mas afirmando também que nem toda palavra possui, de partida, um significado lógico, posto que a correspondência lógica da palavra aos fenômenos reais 
resulta do lento e complexo processo de apropriação da cultura e formação de conceitos. Ou seja, o significado da palavra não é constante posto que a conexão entre pensamento e linguagem também não o é, de sorte que a estrutura semântica que sustenta a consciência se modifica e se desenvolve, na dependência da atividade que vincula sujeito e objeto e sustenta a dinâmica do sistema psíquico.

Conforme disposto por Vygotski em artigo intitulado "O problema da consciência", datado de 1933, o significado da palavra - e a partir dela, os inúmeros significados atribuídos aos fenômenos experienciados, refrata uma dada estrutura de generalização. Toda generalização, por sua vez, resulta de critérios que destacam propriedades específicas e regulares entre objetos/fenômenos e tais princípios não são estáticos, mas mudam e se transformam ao longo da vida, conduzindo, consequentemente, a mudanças nas estruturas de generalização e nos próprios significados delas resultantes.

Seguindo essa linha de raciocínio, o autor afirma que as relações interfuncionais engendram os significados, isto é, a atividade da consciência, por conseguinte, a estrutura do significado resulta condicionada pela estrutura da consciência como sistema. Destarte, Vygotski (1997, p. 129) conclui que “[...] a análise semiótica é o único método adequado para estudar a estrutura do sistema e o conteúdo da consciência." Vygotski (2001) observa, ainda, que o estudo do sistema psíquico e suas funções se justificam não apenas na apreensão do desenvolvimento e formação dos processos psicológicos, mas, sobretudo, quando se trata de sua desintegração, tal como manifesta na psicopatologia. Nas alterações dos processos psicológicos o que se verifica é a desintegração dos sistemas complexos edificados ao longo da vida coletiva da pessoa, sobretudo, daqueles de mais recente formação. Por isso, via de regra, em situação de alteração mental os conteúdos e modos de comportamento de mais remota formação (conteúdos infantis) se destacam, passando a ocupar o lugar da estrutura semântica da consciência radicada prioritariamente em funções psíquicas formados no processo de apropriação da cultura, ou seja, em funções psíquicas superiores.

\section{Considerações finais}

Na perspectiva vigotskiana a análise da consciência demanda: o reconhecimento de seus vínculos com o sistema instituído pelas funções psíquicas; a clareza de que são os signos que modificam as relações interfuncionais; reconhecer que sua manifestação e seu alcance refletem um aspecto qualitativo do psiquismo humano. O domínio 
consciente sobre a imagem psíquica amplia o alcance da mesma, dado que torna a consciência uma via de acesso imprescindível ao objeto que reflete. Todavia, a imagem consciente do objeto/vivência não é sinônimo do mesmo, de sorte que entre objeto e imagem não existe correspondência absoluta. Por isso, toda imagem conterá dimensões consciente e inconsciente.

O sistema psíquico opera, continuamente, a formação de imagens e cabe notar que o grau de iluminação (consciência) da imagem resulta dependente do grau/qualidade da percepção, da atenção, da memória e, sobretudo, da representação conceitual/verbal do fenômeno e de sua tonicidade afetiva, o que permite inferir o inconsciente como polo oposto e interior à própria consciência. Ilustra essa hipótese o fato de que comportamentos automatizados (a exemplo de tarefas sensitivo-motoras) possam ocorrer sem mediação voluntária e direcional da consciência. Há que se reconhecer lacunas e descontinuidades lógicas na formação da imagem subjetiva da realidade objetiva, o que conduz à constatação de inúmeras influências inconscientes no psiquismo e no comportamento humano. A tomada de consciência não deixa de ser, assim, uma luta sem tréguas contra seu oposto.

Ademais, haja vista a estrutura semântica da consciência, a produção vigotskiana lança luz ao estabelecimento de relações fundamentais entre o desenvolvimento da fala e os domínios conscientes acerca da imagem subjetiva da realidade objetiva. Há que se considerar que nos momentos iniciais de vida, as marcas das experiências resultam sob a forma de impressões sensoriais carentes de significados, mas não por isso deixam de existir e influenciar o conjunto de representações em formação.

À medida do desenvolvimento da linguagem, na qualidade de sistema de signos, tais impressões sensoriais integram-se, ou não, ao sistema conceitual em construção e, deste percurso resulta um fato de significativa importância para a análise da dinâmica consciente/inconsciente, qual seja: se nos momentos iniciais de vida a vivência condiciona os fatos que culminam como marcas sensoriais, no transcurso da formação do sistema conceitual os fatos a se fazerem representados destacam-se em função de relações com o referido sistema, e não dos fatos em si mesmos - a percepção se torna categorial e abre possibilidades para inúmeras formas de generalização. Por conseguinte, o dado nuclear na análise da personalidade radica na relação ativa da pessoa com seu entorno físico e social, pela qual se apropria dos significados culturais atribuindo-lhes um sentido particular e único, radicado em sua própria experiência pessoal. 
Outro dado que podemos inferir a partir das proposições vigotskianas diz respeito ao papel que a educação escolar exerce sobre a formação do psiquismo humano, sobretudo ao assumir como tarefa precípua a formação de conceitos. Os conteúdos escolares, na condição de universo simbólico disponibilizado aos indivíduos, operam como signos que se interpõem na relação ativa sujeito/objeto e, potencialmente, ampliam a captação do objeto no conjunto de determinações que sustentam sua existência concreta, o que significa dizer: ampliam a consciência sobre os mesmos. Ao fazê-lo, a formação escolar incide diretamente na formação da capacidade de raciocínio, convocando operações lógicas de análise, síntese, comparações, generalizações e abstrações.

Destarte, os conteúdos de ensino carecem exigir tais operações lógicas, e a probabilidade de que o façam é sobejamente maior quando tais conteúdos superam as esferas dos conceitos cotidianos e de senso comum, avançando em direção aos conceitos científicos, cuja formação subjuga-se a expedientes psíquicos não requeridos na formação espontânea de conceitos, a exemplo da voluntariedade, da atenção focal, da memória lógica, do pensamento rigorosamente teórico e, sobretudo, do autodomínio da conduta. Não sem razão, Martins (2013), em obra intitulada $O$ desenvolvimento do psiquismo e a educação escolar: contribuições à luz da psicologia histórico-cultural e da pedagogia histórico-crítica, afirma que a formação de conceitos científicos não incide apenas na aprendizagem dos aspectos específicos dos conteúdos das disciplinas escolares que os veiculam, posto exercer decisiva influência na formação de estruturas mentais mais gerais, isto é, nos fundamentos da consciência e da personalidade do indivíduo.

Conclui-se desse estudo: a) o conteúdo da consciência é dado pelo significado da palavra - o não verbal resulta oculto e foge ao controle consciente; b) o significado da palavra se forma e se transforma na relação ativa sujeito-objeto; c) características específicas do desenvolvimento do sistema psíquico interfuncional operam sobre os conteúdos da consciência; d) o psiquismo humano não se limita à sua vertente consciente, por isso é licito considerar que o inconsciente é potencialmente consciente e vice versa; e) a qualidade dos conteúdos escolares é variável interveniente no desenvolvimento psíquico e, consequentemente, na formação da consciência dos indivíduos. 
DYNAMICS CONSCIOUS /UNCONSCIOUS IN THE LIGHT OF HISTORICAL AND CULTURAL PSYCHOLOGY

Abstract: The study of conscious and unconscious dimensions of the human psyche, marks the own origins of psychology. Prevalent approaches, now about one dimension, now about other, led to different and antagonistic interpretations that were, over time, establishing itself in the various headquarters, or approaches, the psychological thought. According to Vygotsky and followres the dichotomous paths trodden by psychology determined logical and methodological changes with a view to expanding the principles for structuring own psychological science. With this commitment, they are led towards the systematization of cultural-historical theory, basing it in the materialist-dialectical methodological principles. In this way, they gave the human psyche a unitary approach, in which the conscious and unconscious dimensions result perceived as polar opposites, nevertheless interior to each other. In light of this theoretical framework, this study aims to present the historical and dialectical conception of conscious / unconscious dynamics, in order to contribute to the systemic analysis of psychic phenomena. It is concluded from this study: the content of consciousness is given by the meaning of the word - the verbal results not hidden and beyond the conscious control; the meaning of the word is formed and becomes the active subject-object; the human psyche is not limited to your conscious side, so it is permissible to consider that the unconscious is potentially conscious and vice versa.

Key words: Psychology historical-cultural. Psyche. Conscience. Unconscious.

\section{REFERÊNCIAS}

MARTINS, L.M. A formação social da personalidade do professor: um enfoque vigotskiano. 2. ed. Campinas: Autores Associados, 2015.

MARTINS, L.M. O desenvolvimento do psiquismo e a educação escolar: contribuições à luz da psicologia histórico-cultural e da pedagogia histórico-crítica. Campinas: Autores Associados, 2013.

VYGOTSKI, L. S. Obras escogidas. Madrid: Visor, 2001. Tomo II.

VYGOTSKI, L. S. Obras escogidas. Madrid: Visor, 1997. Tomo I.

VYGOTSKI, L. S. Obras escogidas. Madrid: Visor, 1996. Tomo IV.

VYGOTSKI, L. S. Obras escogidas. Madrid: Visor, 1995. Tomo III. 